\title{
Characterization of Conjugated Polymer Actuation under Cerebral Physiological Conditions
}

\author{
Eugene Dariush Daneshvar and Elisabeth Smela*
}

Conjugated polymer actuators have potential use in implantable neural interface devices for modulating the position of electrode sites within brain tissue or guiding insertion of neural probes along curved trajectories. The actuation of polypyrrole (PPy) doped with dodecylbenzenesulfonate (DBS) is characterized to ascertain whether it can be employed in the cerebral environment. Microfabricated bilayer beams are electrochemically cycled at either 22 or $37{ }^{\circ} \mathrm{C}$ in aqueous NaDBS or in artificial cerebrospinal fluid (aCSF). Nearly all the ions in aCSF are exchanged into the PPy-the cations $\mathrm{Na}^{+}, \mathrm{K}^{+}, \mathrm{Mg}^{2+}, \mathrm{Ca}^{2+}$, as well as the anion $\mathrm{PO}_{4}{ }^{3-} ; \mathrm{Cl}^{-}$is not present. Nevertheless, deflections in aCSF are comparable to those in NaDBS and they are monotonic with oxidation level: strain increases upon reduction, with no reversal of motion despite the mixture of ionic charges and valences being exchanged. Actuation depends on temperature. Upon warming, the cyclic voltammograms show additional peaks and an increase of $70 \%$ in the consumed charge. Bending is, however, much less affected: strain increases somewhat $(6 \%-13 \%)$ but remains monotonic, and deflections shift (up to $20 \%$ ). These results show how the actuation environment must be taken into account, and demonstrate proof of concept for actuated implantable neural interfaces.

\section{Introduction}

Conjugated polymers are a class of so-called "intelligent" materials because they respond to electrical stimuli and to their external environments. One response is a change in volume, which has led to their use as actuators. Several factors make such actuators promising for biomedical applications, as reviewed elsewhere ${ }^{[1]}$ and there have been demonstrations of this, both in vitro and in vivo. ${ }^{[2-6]}$ Conjugated polymers have been shown to be biocompatible, ${ }^{[7-9]}$ and their low actuation voltages $(<1 \mathrm{~V})$ are considered benign for interactions with biological tissues. ${ }^{[3,9,10]}$ These actuators can exert substantial forces ${ }^{[11,12]}$ because of their high elastic moduli $(0.1-100 \mathrm{GPa}) .^{[1,13]}$ In addition, they can be readily integrated with standard microfabrication processes. ${ }^{[14]}$

\footnotetext{
Dr. E. D. Daneshvar

Department of Biomedical Engineering

University of Michigan

Ann Arbor, MI 48109, USA

Prof. E. Smela

Department of Mechanical Engineering

University of Maryland

College Park, MD 20742, USA

E-mail: smela@umd.edu
}

DOI: 10.1002/adhm.201300610
For actuation, polypyrrole (PPy) is one of the most commonly used conjugated polymers. In our laboratory, we have often used PPy doped with dodecylbenzenesulfonate, $P P y(D B S)$. The immunoreactivity of $\mathrm{PPy}(\mathrm{DBS})$ has previously been shown by histological testing to be favorable..$^{[3,9,10]}$ Although gradually degraded by operation in aqueous electrolytes, PPy(DBS) is stable for short-term use (up to several thousand cycles).$^{[15]}$

Motivating the work presented here is the possibility of augmenting implantable neural interface devices with controllable bending elements. Adjusting the position of electrode sites within neural tissue to change electrode proximity to particular neurons may be beneficial for several reasons. For neural recording devices, the ability to move the electrode out of a damaged region may result in increased signal to noise ratios. ${ }^{[16]}$ For neural stimulating devices, more accurate electrode placement may increase treatment efficacy and lower the charge injection required for stimulation. ${ }^{[17,18]}$ In addition, actuators may be used to guide the insertion of neural probe devices, allowing non-straight trajectories and active steering to target structures with precision, as needed for deep brain stimulation therapy. ${ }^{[19]}$ Therefore, it is critical to understand the expected behavior of the actuator in the cerebral environment.

We have previously demonstrated the feasibility of using PPy(DBS) to controllably bend neural electrodes within an agarose brain phantom during their insertion (Figure 1). ${ }^{[20]}$ Figure 1a shows an array of five probes immediately after fabrication; the beams are bent due to residual stress. The electrode beams in Figure $1 \mathrm{~b}$ were actuated within the brain phantom ( $0.5 \%$ agarose and $0.1 \mathrm{~m}$ NaDBS), which has a stiffness similar to brain tissue. The PPy(DBS) produced sufficient force to move the electrodes out of plane during insertion into the gel, as required for cortical applications. Other applications, such as electrodes for the eye or ear, would operate in aqueous environments and encounter smaller opposing forces. Probes may also be bent at segments acting as joints (Figure 1c), rather than along the entire length. These results were promising for the potential use of conjugated polymers in neural interface devices.

In this paper, we characterize the behavior of the actuators, studying them at body temperature $\left(37^{\circ} \mathrm{C}\right)$ in artificial cerebrospinal fluid (aCSF), which contains a mixture of ions. Actuation in NaDBS at room temperature $\left(22^{\circ} \mathrm{C}\right)$ is used as a comparison 

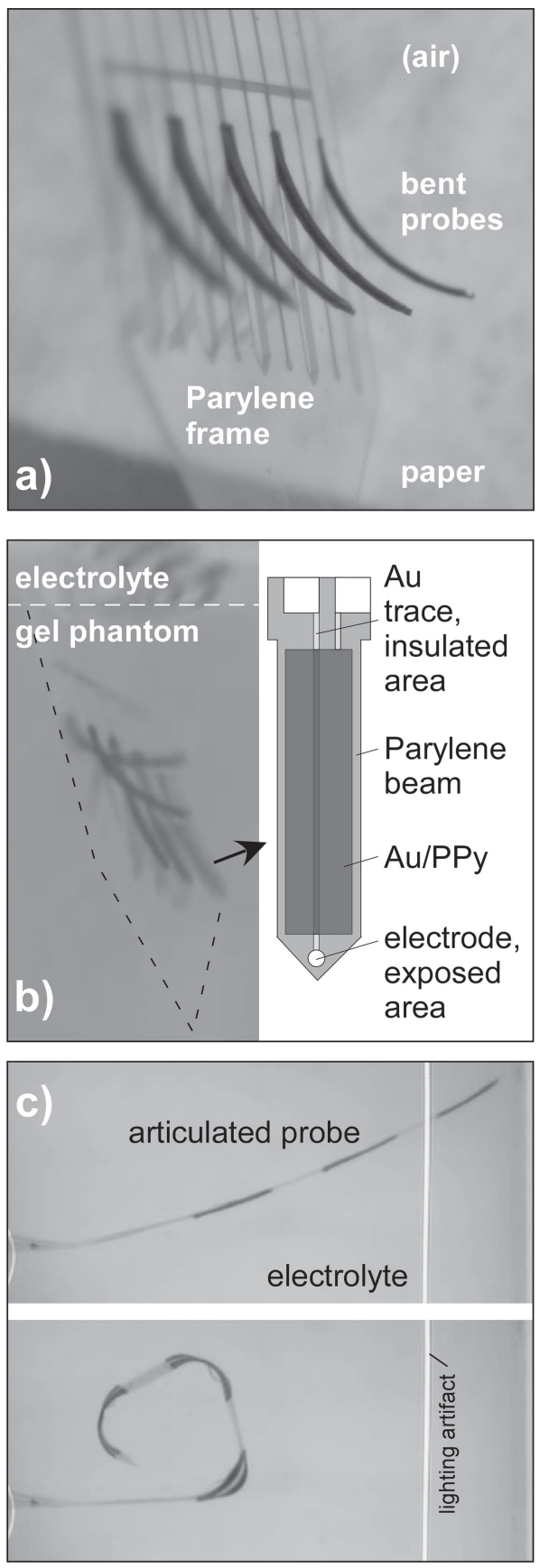

Figure 1. a) An array of five probe devices in air having lengths of $1 \mathrm{~mm}$ and widths between $50 \mu \mathrm{m}$ and $250 \mu \mathrm{m}$, deflected out of plane with uniform curvature after fabrication, with no applied voltage. b) A similar set of probes with lengths of $800 \mu \mathrm{m}$ actuated during penetration into a gel brain tissue phantom. The Parylene probe beams included an insulated electrode trace with an exposed Au electrode site at the tip and an overlying PPy/Au actuator. c) A segmented beam with actuators at three joints, electrochemically reduced to be straight (top) and oxidized to be bent (bottom) in NaDBS solution.

because extensive prior characterization has been performed in this electrolyte. ${ }^{[21-23]}$ We show that the performance is substantially the same, demonstrating that these actuators may be used under physiological conditions.
Actuation strain in aCSF was somewhat smaller than in NaDBS (by a factor of 0.89 at room temperature), and approximately the same charge density was exchanged (102\%). Increasing the temperature to $37^{\circ} \mathrm{C}$ resulted in a small increase in the actuation strain (by $13 \%$ in NaDBS and $6 \%$ in aCSF), but also a significant increase in the exchanged charge (by $\approx 67 \%$ in both cases). Elemental analysis showed that in addition to $\mathrm{Na}$, samples cycled in aCSF contained $\mathrm{Mg}, \mathrm{Ca}, \mathrm{K}, \mathrm{P}$, and $\mathrm{O}$ (from $\mathrm{PO}_{4}{ }^{3-}$ and its protonated forms), but no $\mathrm{Cl}$. Despite the substantial amount of $\mathrm{PO}_{4}{ }^{3-}$, the actuation remained monotonic with voltage and did not reverse due to anion ingress and egress.

\subsection{Conjugated Polymer Actuators}

Conjugated polymers such as PPy are characterized by alternating single and double bonds between the carbon atoms along the polymer backbone. ${ }^{[1,24]}$ Mobile positive charges are produced when electrons are removed from the charge-neutral polymer (i.e., when the polymer is oxidized), making the material electrically conducting. PPy is electropolymerized in the oxidized ("doped") state. Therefore, to maintain overall charge neutrality during film deposition, negatively charged anions are incorporated into the matrix. A large number of anions are incorporated: one for every 3-4 pyrrole units. ${ }^{[25]}$ The anions therefore strongly influence the structure of the material, and thus the mechanical and electrical properties. It is thus necessary to specify the anion used during deposition when naming the polymer; $\mathrm{PPy}(\mathrm{DBS})$ and $\mathrm{PPy}\left(\mathrm{ClO}_{4}\right)$ have quite different microstructures and behaviors.

Oxidation can be achieved electrochemically, and it is reversible: applying a sufficiently negative potential returns the electrons to the polymer, reducing it to the neutral state. To maintain charge neutrality in the material, the dopant anions are expelled into the surrounding electrolyte, if the anions are small enough (such as $\mathrm{ClO}_{4}^{-}$); these are anionexchanging polymers. Alternatively, if the anions that were incorporated during polymerization are too large to exit (such as DBS $^{-}$) and are thus entrapped in the polymer, then during reduction cations are pulled in by the electrostatic forces (cation-exchanging polymers). The exit or influx of ions, each surrounded by a "shell" of solvent (which is water in biomedical applications), causes a change in polymer volume that can be harnessed to perform mechanical work. (It also results in a change in the elastic modulus as a function of oxidation level. $]^{[23,26]}$

The actuation strain is the change in length divided by original length, $\Delta L / L$, that would occur in a free-standing film due to redox. It is positive upon ion and solvent influx, and its magnitude depends on the number of solvent molecules accompanying the ion in its solvation shell. In cation-exchanging materials, lower atomic weight cations, which have a higher charge density and are thus surrounded by larger hydration shells, ${ }^{[27]}$ produce greater force, ${ }^{[28]}$ and displacement. ${ }^{[21,28,29]}$

Divalent cations interact more strongly with the polymer than monovalent cations, and they have a lower mobility. ${ }^{[22]}$ In other systems, they have been shown to electrostatically crosslink ionic polymer chains. ${ }^{[30]}$ Divalent cations may require a 
stronger driving force (electrochemical potential) for insertion into or expulsion from the conjugated polymer ${ }^{[31]}$ and result in less expansion during polymer reduction. ${ }^{32]}$

$\mathrm{PPy}(\mathrm{DBS})$ is one example of a cation-exchanging material, and it has been previously characterized in some depth upon cycling in aqueous $\mathrm{NaCl}$ and $\mathrm{NaDBS}$. In aqueous solutions containing $\mathrm{Na}^{+}$, the actuation strain $\alpha$ in the plane of the film (inplane, i.e., parallel to the surface) is approximately $3 \%$ in the bulk. ${ }^{[21,33]}$ The inplane actuation strain is what leads to bending in bilayer actuators. (The out-of-plane actuation strain (perpendicular to the surface) in thin films can be ten times larger. $)^{[34]}$

Small anions, such as $\mathrm{Cl}^{-}$, may also participate in charge balance in $\mathrm{PPy}(\mathrm{DBS})$, becoming incorporated during oxidation and ejected during reduction. ${ }^{[32,35-37]}$ These typically have a different mobility in the polymer than the cations and a different potential window in which they are exchanged. The simultaneous transport of anions and cations in opposite directions at different speeds can result in a reversal in the strain direction. ${ }^{[38-40]}$ Non-monotonic motion is problematic for control over actuator position.

Temperature has also been found to play a role in actuation. Actuators operating at elevated temperatures showed greater strain $^{[41,42]}$ and accelerated creep. ${ }^{[43]}$

Conjugated polymer actuator performance therefore depends not only on the synthesis medium but also on the medium in which it is employed. Because the roles of the electrolyte and the temperature are not yet fully understood, new operation conditions must be characterized in terms of critical performance characteristics such as actuation strain, actuation stress (or, in the case of bending bilayers, moment), and speed. In this paper, we characterize actuation strain. (Some information on speed has been included in the Supporting Information.)

\subsection{Actuation in Cerebral Physiological Ion Concentrations and Temperature}

The prior demonstrations of biomedical applications ${ }^{[2-6]}$ did not characterize actuation strain or deflection in those media. PPy(DBS) actuation has, however, been tested in several ionic solutions and temperature ranges. The majority of these studies have been done by systematically cycling one cation at a time ${ }^{[41,44,45]}$ or by cycling in a solution with a single anion and cation, such as $\mathrm{NaCl} .^{[46,47]} \mathrm{PPy}(\mathrm{DBS})$ has not yet been characterized in the ionic mixture and temperature found in the brain. For the long-term goal of producing movable neural interfaces, performance in cerebrospinal fluid (CSF) at body temperature needs to be determined. Ion concentrations in CSF are listed in Table 1. The primary constituents are $\mathrm{Na}^{+}$and $\mathrm{Cl}^{-}$. CSF also contains glucose, proteins $\left(430 \mathrm{mg} \mathrm{L}^{-1}\right)$, and lymphocytes $\left(<4 \mu \mathrm{m}^{3}\right)$, and it is maintained at a $\mathrm{pH}$ of $7.31 .{ }^{[48,49]} \mathrm{aCSF}$ is used in lab settings to match the electrolyte concentrations of CSF, but it lacks the other components. This study examined the effects of the mixed ionic components of CSF on actuation, but future work will need to examine the effects of the other components, also.
Table 1 Ionic components of artificial cerebrospinal fluid. [48]

\begin{tabular}{lccc}
\hline CSF ionic component & $\begin{array}{c}\text { Hydrated radius } \\
{[\mathrm{pm}]^{[27]}}\end{array}$ & $\begin{array}{c}\text { Concentration } \\
{[\mathrm{mm}]}\end{array}$ \\
\hline Sodium & $\mathrm{Na}^{+}$ & 450 & $135-150$ \\
Chlorine & $\mathrm{Cl}^{-}$ & 300 & $115-130$ \\
Potassium & $\mathrm{K}^{+}$ & 300 & $2.6-3.0$ \\
Calcium & $\mathrm{Ca}^{2+}$ & 600 & $1.0-1.4$ \\
Magnesium & $\mathrm{Mg}^{2+}$ & 800 & $1.2-1.5$ \\
Phosphate & $\mathrm{PO}_{4}{ }^{3-}{ }^{*}$ & 400 & $0.4-0.6$ \\
\hline
\end{tabular}

"The charge depends on $\mathrm{pH}$, going from $\mathrm{PO}_{4}{ }^{3-}$ at high $\mathrm{pH}$ to $\mathrm{H}_{3} \mathrm{PO}_{4}$ at low $\mathrm{pH}$.

\section{Results and Discussion}

\subsection{Deflection During Cyclic Voltammetry in NaDBS at Room Temperature}

The cycling behavior of PPy(DBS) in aqueous NaDBS at room temperature was used as a baseline because this polymer has previously been characterized in this electrolyte. ${ }^{[23,56]}$ Since the DBS $^{-}$is not exchanged, only the $\mathrm{Na}^{+}$contributes to the volume change, ${ }^{[36,57]}$ causing an expansion (and thus bilayer bending PPy-side out) during reduction as the hydrated $\mathrm{Na}^{+}$enters the polymer and a contraction (bending PPy-side in) during oxidation as the hydrated $\mathrm{Na}^{+}$leaves the polymer. $\left(\mathrm{OH}^{-}\right.$in the solution also enters and exits the polymer, but it does not contribute to actuation. $)^{[58]}$

Twelve bilayer devices were initially cycled 10 times (cycles $1-10)$ in NaDBS at room temperature $\left(\mathrm{RT} \approx 22^{\circ} \mathrm{C}\right.$ ) from +0.4 to $-1.0 \mathrm{~V}$ versus $\mathrm{Ag} / \mathrm{AgCl}$ at $10 \mathrm{mV} \mathrm{s}^{-1}$ to bring them all to the same starting condition. (The samples were "primed"). The NaDBS concentration was $0.15 \mathrm{M}$, matching the cation concentration in CSF. Sample-to-sample variation in the bending of these nominally identical samples is shown in the Supporting Information.

Figure 2 shows the deflection versus time of one of the bilayers during the initial cycling in NaDBS at RT. The samples began (at $t=-40 \mathrm{~s}$ ) curved with the PPy side out (bending "backwards"). This curvature is not seen in thinner films of $1 \mu \mathrm{m},{ }^{[59]}$ but is consistently observed in bilayers with thicker PPy films. During the initial increase in potential from 0 to $+0.4 \mathrm{~V}$ (to the left of the first dashed vertical line), the deflection increased somewhat, indicating a small expansion of the PPy. The gradual increase in deflection continued upon scan reversal to the reduced state at $-1.0 \mathrm{~V}(t=150 \mathrm{~s})$. Such a lack of significant bilayer movement during the first reduction scan, despite the influx of $\mathrm{Na}^{+}$, is typical of $\mathrm{PPy}(\mathrm{DBS}),{ }^{[58,60]}$ which expands out-of-plane at this time. ${ }^{[61]}$ Upon re-oxidation (going from -1.0 to $+0.4 \mathrm{~V}$ ), the PPy contracted strongly inplane as the $\mathrm{Na}^{+}$was expelled, reversing the direction of bending so that the PPy faced in (shown by negative numbers on the axis), passing through a point at which the bilayer was flat. Thereafter, the second reduction led to an expansion back to nearly the original position. The deflection versus time curves stabilized after the third or fourth cycle. This behavior is consistent with prior work, in terms of general behavior and the number of cycles required for "break in" (or priming or conditioning). 


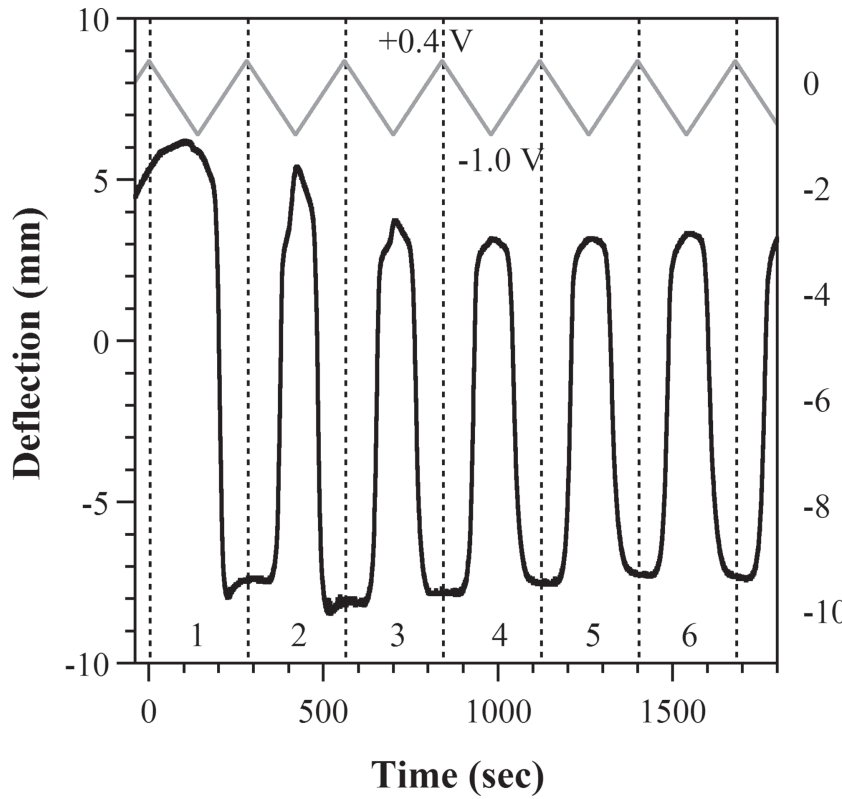

Figure 2. Deflection vs time (lower black curve) during the first six cycles (numbered) of a bilayer in NaDBS at room temperature. The voltage was scanned at $10 \mathrm{mV} \mathrm{s}^{-1}$ between +0.4 and $-1.0 \mathrm{~V}$ vs $\mathrm{Ag} / \mathrm{AgCl}$, as illustrated at the top (gray curve). Positive deflection indicates PPy expansion (bending PPy-side out), and negative deflection indicates PPy contraction (PPy-side in).

\subsection{Cyclic Voltammograms Under Four Conditions}

Immediately after the priming step, the samples were split into four groups of three samples each and cycled ten times (cycles 11-20) as before but in either 1) NaDBS at room temperature (NaDBS at RT), or 2) NaDBS at body temperature (NaDBS at $\left.37^{\circ} \mathrm{C}\right)$, 3) the physiological electrolyte at room temperature (aCSF at RT), or 4) the physiological electrolyte at body temperature $\left(\mathrm{aCSF}\right.$ at $\left.37^{\circ} \mathrm{C}\right)$. The cyclic voltammograms (CVs) and the associated deflections during scan 19 in the four solutions are shown for representative samples in Figure 3. (Scan 20 concluded at $0 \mathrm{~V}$, so to compare the deflection and charge consumed with scans ending at full oxidation $(0.4 \mathrm{~V})$, scans 9 and 19 were taken as representative of the steady state. The CVs for all 20 scans of all 12 samples are shown in the Supporting Information.)

The CV for NaDBS at RT (Figure 3a, the control) was as expected from prior work, ${ }^{[29]}$ with a reduction peak near $-0.45 \mathrm{~V}$ and an oxidation peak at $-0.15 \mathrm{~V}$ with a shoulder visible near $-0.35 \mathrm{~V}$. Table 2 shows average values for the three samples in each group of the exchanged charge in both the priming step and, as ratios, in the subsequent cycling under the four conditions. (Values for all groups of samples during scans 9 and 19 are included in the Supporting Information.) Comparing the average charge densities consumed by these samples during cycle 19 compared with cycle 9 (Table 2, data line 6), there was a $9 \%$ increase. Variations between samples were of similar magnitude, so we do not consider this $9 \%$ to be significant.

At $37{ }^{\circ} \mathrm{C}$, the CVs of the devices cycled in NaDBS changed significantly (Figure 3b). There was now a large oxidation peak at $-0.35 \mathrm{~V}$ (the position at which the shoulder had been at RT), and a second broad oxidation peak appeared that was centered around $+0.1 \mathrm{~V}$; there was no clear peak at $-0.15 \mathrm{~V}$. In addition, two more reduction peaks appeared to the right of the peak at -0.45 , at -0.35 and $-0.25 \mathrm{~V}$. The area bounded by the CV was significantly larger: the exchanged charge density was $66 \%$ greater when cycling at $37^{\circ} \mathrm{C}$ than at RT.

The CVs in aCSF at RT (Figure $3 \mathrm{c}$ ) varied in their oxidation peak positions among the three samples, so two examples are shown. In general, the CVs were similar to those in NaDBS at RT, but the reduction peak was shifted slightly $(30 \mathrm{mV})$ cathodically (i.e., to the left), and the oxidation peak was shifted anodically (to the right) in two cases but not the third. The total exchanged charge density was virtually the same as in NaDBS at RT.

Upon increasing the temperature in aCSF (Figure 3d), the changes in the oxidation current mirrored those in NaDBS at $37^{\circ} \mathrm{C}$ (Figure $3 \mathrm{~b}$ ), and again the position of the large peak was shifted anodically relative to the one in NaDBS at $37^{\circ} \mathrm{C}$. The two satellite peaks during reduction were not present, however. (The CVs are overlaid for ease of comparison in the Supporting Information.) The total exchanged charge density again increased compared to aCSF at RT, by a similar factor (70\%) as seen in NaDBS.

\subsection{Actuation Strains During CVs}

Given the significant changes in the CVs, the important question was whether there were similar significant changes in actuation strain. In $\mathrm{PPy}\left(\mathrm{ClO}_{4}\right)$ more exchanged charge is associated with greater strain, until a degradation point, ${ }^{[62,63]}$ but in $P P y(D B S)$ currents can flow that are not associated with volume change. ${ }^{[64]}$ Returning again to Figure 3a but this time examining the associated deflection, the contraction of the PPy (note the reversed right axis) began simultaneously with the onset of the oxidation current (shown by the dotted black arrow on the left), slowing down after the peak as the current dropped but continuing to $+0.4 \mathrm{~V}$. Expansion was also concurrent with the flow of charge during reduction (dashed black arrow) and continued all the way to $-1.0 \mathrm{~V}$.

As shown in Table 2 (data line 3, column 2), the average net strain (found using Equation 1 from the displacements) in NaDBS at RT was only $0.7 \%$, substantially less than the previously reported $\approx 3 \% .[23,33,35]$ The reasons for this are unclear. The maximum voltages experienced during deposition were below $+0.55 \mathrm{~V}$ versus $\mathrm{Ag} / \mathrm{AgCl}$, so the PPy films were not over-oxidized. Samples were examined by SEM at crosssections midway through the beams, and beams demonstrating delamination were excluded from the analysis. However, partial delamination cannot be ruled out; this would have reduced the curvature since only part of the PPy film would have contributed to actuation. PPy films in contact with a conductor along their entire area have been shown to produce a force density sixfold greater than isolated films. ${ }^{[12]}$ There is some evidence for delamination in the CVs shown in the Supporting Information, in which the currents steadily decrease in each cycle and the peak positions shift.

The ratio of the strain to the charge density was on the order of $0.4 \times 10^{-10} \% /\left(\mathrm{C} \mathrm{m}^{-3}\right)$. Previous values (at RT) were 

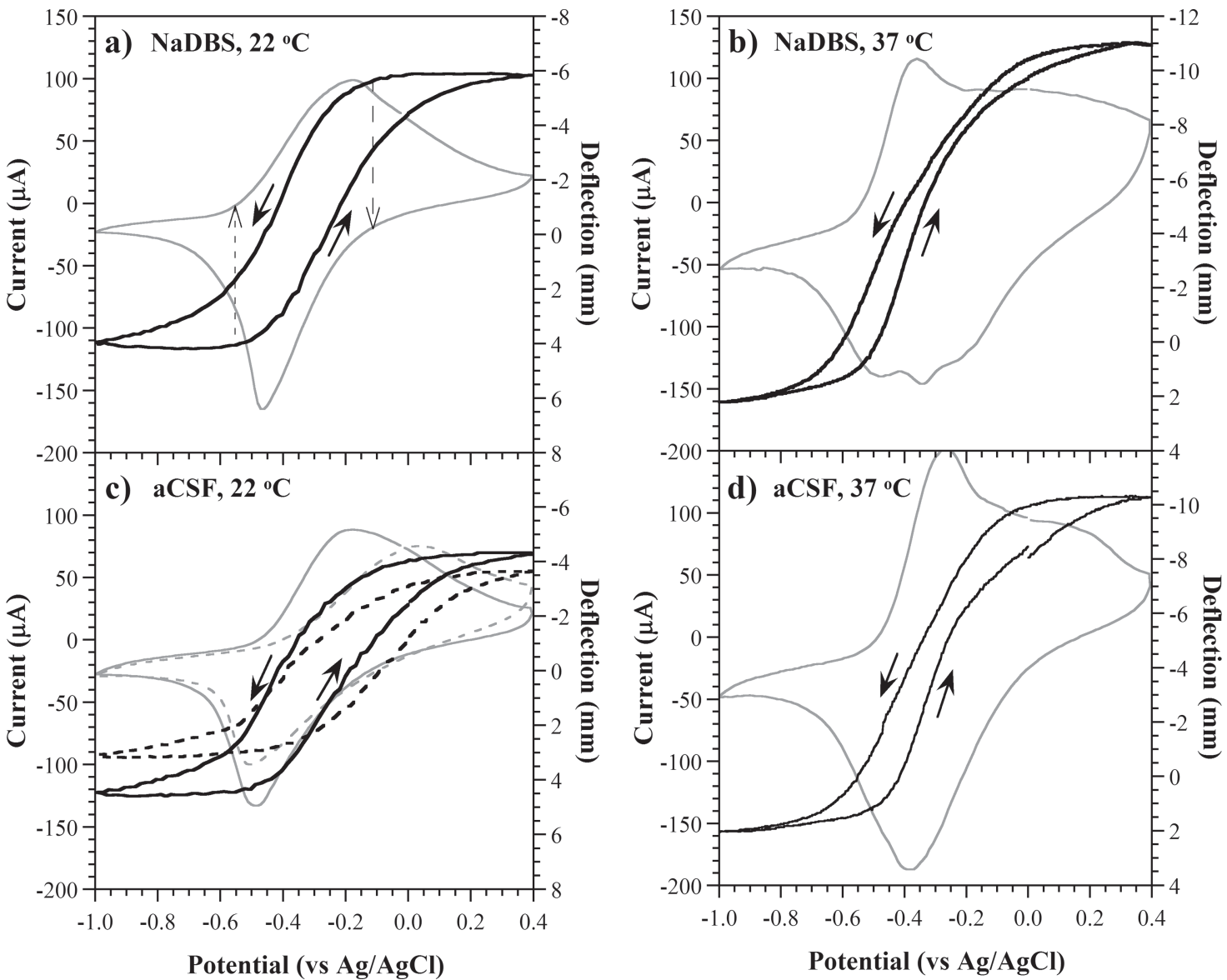

Figure 3. Current (gray line) and displacement (thicker black line) as a function of potential during the $19^{\text {th }} \mathrm{CV} \mathrm{scan}$ at $10 \mathrm{mV} \mathrm{s} \mathrm{s}^{-1}$ under four conditions. The direction of the scan for the displacement curves is indicated by arrows; note that this axis has been reversed to facilitate comparison with the current. The deflection axis is shifted in (b) and (d) relative to (a) and (c), but has the same amplitude (16 mm). The dashed lines in (c) show results from a second sample.

$3 \mathrm{x}$ as high for PPy(tetraethylammonium hexafluorophosphate) at $1.2-1.4 \times 10^{-10} \% /\left(\mathrm{C} \mathrm{m}^{-3}\right)$ (electro-polymerized, cycled in propylene carbonate) ${ }^{[65,66]}$ and two orders of mag- nitude higher for PPy(sodium benzenesulfonate) at $30 \times$

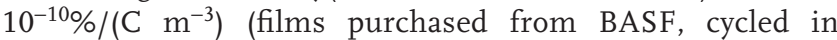
acetonitrile). ${ }^{[67,68]}$

Table 2. Values of average actuation strain $\alpha$, exchanged charge density, and strain-to-charge density in the ninth scan in NaDBS (12 samples) and average ratios of the $19^{\text {th }}$ to the $9^{\text {th }}$ scans under different cycling conditions ( $n=3$ unless otherwise noted).

\begin{tabular}{|c|c|c|c|c|c|c|}
\hline \multirow[t]{2}{*}{ Measurements } & \multicolumn{2}{|c|}{ Values in NaDBS, Scan 9} & \multicolumn{4}{|c|}{ Ratio of scans $19 / 9$} \\
\hline & & & $\mathrm{NaDBS}$ & $\mathrm{NaDBS}$ & $\mathrm{aCSF}$ & aCSF \\
\hline & & & $\mathrm{RT}$ & $37^{\circ} \mathrm{C}$ & $\mathrm{RT}$ & $37^{\circ} \mathrm{C}$ \\
\hline$\alpha$ reduction & 0.37 & $\%$ & $1.09 \pm 0.43$ & $0.58 \pm 0.09$ & $0.86 \pm 0.33$ & $0.40 \pm 0.28$ \\
\hline$\alpha$ oxidation & -0.36 & $\%$ & $0.93 \pm 0.42$ & $1.53 \pm 0.18$ & $0.93 \pm 0.31$ & $1.28 \pm 0.22$ \\
\hline$\alpha$ total & 0.73 & $\%$ & $1.02 \pm 0.40$ & $1.13 \pm 0.09$ & $0.89 \pm 0.32$ & $0.94 \pm 0.19$ \\
\hline Re charge density & $-98 \pm 14 \times 10^{6}$ & $\mathrm{C} \mathrm{m}^{-3}$ & $1.11 \pm 0.18$ & $1.78 \pm 0.42$ & $1.02 \pm 0.20$ & $1.68 *$ \\
\hline Ox charge density & $79 \pm 11 \times 10^{6}$ & $\mathrm{C} \mathrm{m}^{-3}$ & $1.06 \pm 0.21$ & $1.56 \pm 0.26$ & $1.01 \pm 0.19$ & $1.71 *$ \\
\hline Total charge density & $178 \pm 24 \times 10^{6}$ & $\mathrm{C} \mathrm{m}^{-3}$ & $1.09 \pm 0.18$ & $1.66 \pm 0.30$ & $1.02 \pm 0.23$ & $1.70 *$ \\
\hline $\operatorname{Re} \alpha /$ charge density & $38 \pm 14 \times 10^{-12}$ & $\left|\% /\left(\mathrm{C} \mathrm{m}^{-3}\right)\right|$ & $0.99 \pm 0.42$ & $0.33 \pm 0.09$ & $0.84 \pm 0.36$ & $0.24 \pm 0.17$ \\
\hline Ox $\alpha /$ charge density & $45 \pm 14 \times 10^{-12}$ & $\left|\% /\left(\mathrm{C} \mathrm{m}^{-3}\right)\right|$ & $0.87 \pm 0.43$ & $0.98 \pm 0.20$ & $0.92 \pm 0.35$ & $0.75 \pm 0.13$ \\
\hline Tot $\alpha /$ charge density & $41 \pm 14 \times 10^{-12}$ & $\left|\% /\left(\mathrm{C} \mathrm{m}^{-3}\right)\right|$ & $0.94 \pm 0.40$ & $0.68 \pm 0.13$ & $0.87 \pm 0.37$ & $0.55 \pm 0.11$ \\
\hline
\end{tabular}

*Denotes data from one sample. 
As it should have, the average net strain remained effectively unchanged from cycle nine to cycle 19 in NaDBS at RT $(2 \%$ increase - Table 2 , line 3 , column 3 ), although there was a small shift in the position; this is discussed in more detail below. The average consumed charge increased by $9 \%$, leading to a somewhat smaller strain to charge ratio (6\% decrease). These variations provide context for interpreting the magnitude of changes under the other cycling conditions, since nominally the conditions were unchanged here from the priming conditions: variations of this size should not be considered meaningful, but due to experimental variations.

The overall actuation behavior in aCSF at RT (Figure 3c) could be described in the same way as in NaDBS. The actuation strain decreased somewhat $(-11 \%$ relative to scan nine for this group of devices in NaDBS) while the current density was unchanged, resulting in a correspondingly smaller strain to charge ratio. Most importantly, there was no reversal in the direction of movement despite the anions in this solution, and no significant loss of strain over time due to the divalent cations.

Despite the substantial changes in the CVs when the temperature was raised to $37{ }^{\circ} \mathrm{C}$ in $\mathrm{NaDBS}$, the actuation strain varied relatively little from that at RT, increasing by a factor of 1.13 on average. (The particular sample in Figure 3b increased much more; the other two pairs of curves are shown in the Supporting Information.) Because of the large increase in the consumed charge (66\%), the strain-to-charge ratio dropped to 0.68 of the value at RT. At elevated temperatures, the actuators were thus less efficient in converting electrical energy to mechanical energy. There was also a large shift of several $\mathrm{mm}$ in the positions of the deflections (equilibrium bending angle), as seen by comparing the values of the deflection axis limits in Figure 3a and c. This behavior is further discussed below and needs to be taken into account in designing actuators for use at body temperature. The new oxidation peak at $+0.1 / 0.2 \mathrm{~V}$ did not contribute significantly to the volume change, and again there was no reversal in the direction of movement even though the oxidation process corresponding to that peak has previously been correlated with anion ingress. ${ }^{[22]}$ It is not clear why there is a new oxidation peak unassociated with bilayer motion at $37^{\circ} \mathrm{C}$, and this should be the topic of future investigation.

In aCSF, although $67 \%$ more charge was exchanged at $37^{\circ} \mathrm{C}$ than at $22{ }^{\circ} \mathrm{C}$, the net strain only increased by $6 \%$ on average, reducing the strain to charge density. These results mirrored those in heated NaDBS. Again, there was a shift in the average bending angle.

These experiments show that these actuators behave substantially the same under physiological settings as in NaDBS, with the movement monotonically increasing/decreasing with voltage at these scan rates. Monotonic behavior is important for actuator control, and was a welcome surprise because the presence of $\mathrm{Cl}^{-}$ anions has previously been reported to result in tip deflection in one direction as the cations exit followed shortly thereafter by deflection in the opposite direction as anions enter. ${ }^{[22,69]}$

\subsection{Maximum Deflection During CVs}

As mentioned previously, there were shifts in the average bending angle for the four experimental groups relative to

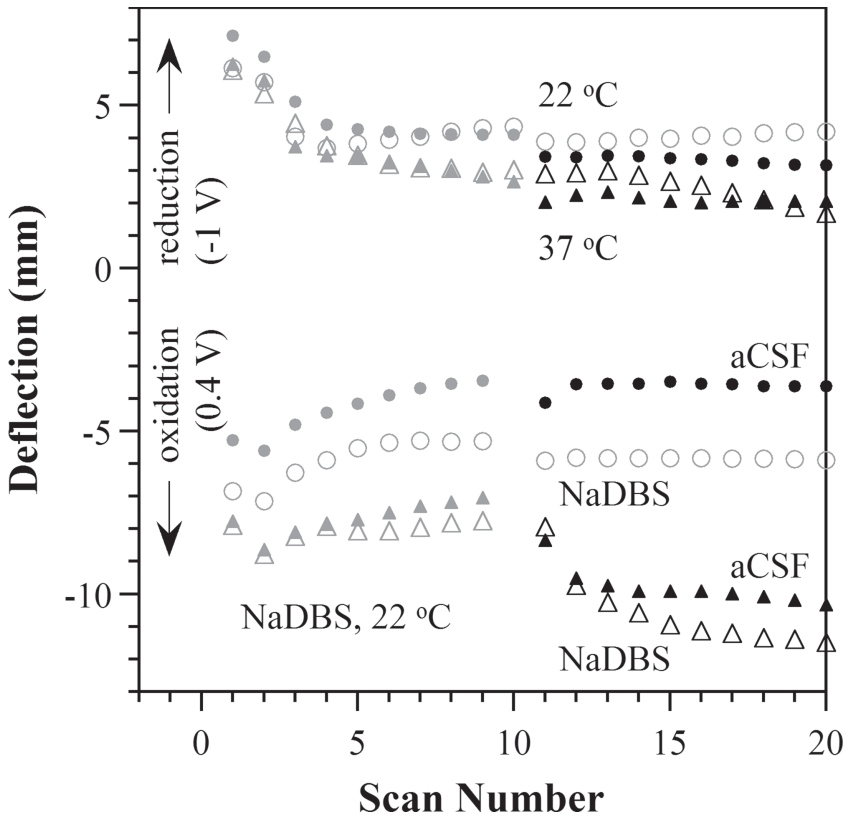

Figure 4. a) Maximum deflection of representative bilayers during oxidation and reduction during cyclic voltammetry as a function of cycle number. Gray symbols: actuation in NaDBS at room temperature (all samples during cycles 1-10). Filled symbols: actuation in aCSF during cycles 11-20; open symbols: actuation in NaDBS; triangle symbols, actuation at $37{ }^{\circ} \mathrm{C}$ during cycles 11-20; circle symbols, actuation at room temperature.

the baseline primed condition. Figure 4 shows the maximum deflections during oxidation and reduction of one representative bilayer in each group of three under each of the four conditions over all $20 \mathrm{CV}$ cycles. (The behavior of the three beams in each set was similar, as demonstrated in the Supporting Information.)

As discussed for Figure 2, during the first several cycles the magnitude of the deflection in both directions decreased, but then it then stabilized. The curves for bilayers that continued cycling in NaDBS at RT (open circles) leveled out to show no further change over time. Those cycled in aCSF at RT (filled circles) experienced an immediate small decrease in total peak-topeak deflection ( $8 \%$ on average), and thereafter the deflections remained constant (leveling off at a $10 \%$ average decrease).

The changes with temperature were larger, as also reflected in Figure 3. Samples cycled at $37{ }^{\circ} \mathrm{C}$ (triangular points) in both aCSF (filled symbols) and NaDBS (open symbols), showed a contraction of the PPy, with both positive and negative deflections shifting relative to the previous cycles; this likely reflects a structural change in the polymer. Deflection during oxidation was more strongly shifted, resulting in an overall net increase in the range of motion by $\approx 2.5 \mathrm{~mm}$. These results are consistent with previously observed increased strain at higher temperatures. ${ }^{[41,42]}$

\subsection{Elemental Analysis}

To shed light on the actuation changes noted above, energy-dispersive X-ray spectroscopy (EDX) was performed. There were 


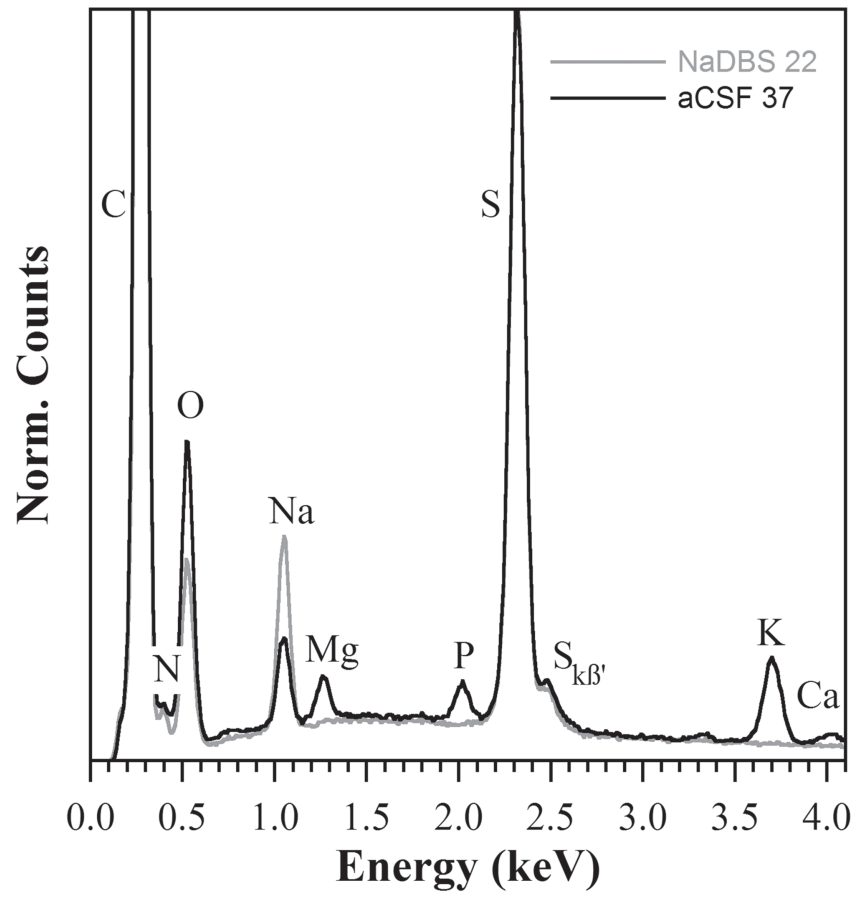

Figure 5. EDX spectra of samples cycled in NaDBS at $22{ }^{\circ} \mathrm{C}$ and in aCSF at $37^{\circ} \mathrm{C}$, normalized to the $\mathrm{S}$ peak.

small variations among the three samples under each condition, so the spectra were averaged. Figure 5 shows the average EDX spectra from the samples that had been cycled in NaDBS at RT and from those cycled in aCSF at $37^{\circ} \mathrm{C}$. The spectra were normalized to the sulfur (S) peak; results were virtually identical using the carbon $(\mathrm{C}$ ) peak. A nickel peak (at $8.26 \mathrm{keV}$, not shown) indicated that the beam penetrated the entire thickness of the sample.

The sample cycled in NaDBS contained carbon (C) from the PPy and the DBS, nitrogen $(\mathrm{N})$ from the PPy, and oxygen $(\mathrm{O})$ and sulfur (S) from the DBS. It also contained sodium (Na) from the electrolyte. Recall that the sample was taken to the oxidized state before removing it from the electrochemical cell, so this reflects $\mathrm{Na}^{+}$that is deeply trapped in the film (presumably with the associated water). A small $S_{\mathrm{k} \beta}$, shift peak, an indication of the $\mathrm{S}$ oxidation state, is also visible to the right of the $\mathrm{S}$ peak. ${ }^{[70]}$ The sample cycled in aCSF contained the same species, but it also showed magnesium $(\mathrm{Mg})$, calcium $(\mathrm{Ca})$, potassium $(\mathrm{K})$, phosphorous $(\mathrm{P})$, and additional oxygen $(\mathrm{O})$ (the latter two from the $\mathrm{PO}_{4}$ ) incorporated into the polymer during cycling. There was no $\mathrm{Cl}$ in these samples $\left(k_{\alpha} 2.622, k_{\beta} 2.815 \mathrm{eV}\right)$ (although we found trace amounts in two samples in a previous study. $)^{[71]}$

EDX is not quantitative without comparison to a reference sample with a similar composition. Furthermore, the areas under EDX peaks for different species cannot be used to obtain relative concentrations, so these spectra can only be used to compare relative amounts of the same element. The area under the Na peak for the sample cycled in aCSF was $68 \%$ of the size for the sample cycled in NaDBS $(72 \%$ if normalizing to the C peak instead of the S peak), so we can hypothesize that a third less $\mathrm{Na}+$ was exchanged during cycling in aCSF. (This conclu- sion assumes that if there was any loss of $\mathrm{Na}^{+}$during sample rinsing and drying, it occurred in the same proportion in both solutions.)

The difference in compensating charge was made up by the other cations. Given their low concentration in aCSF (Table 1), we can conclude that the PPy affinity for $\mathrm{K}^{+}, \mathrm{Ca}^{2+}$, and $\mathrm{Mg}^{2+}$ is higher than for $\mathrm{Na}^{+}$. We have previously shown that $\mathrm{K}^{+}$produces smaller strains than $\mathrm{Na}^{+[44]}\left(\mathrm{K}^{+}\right.$has a smaller hydration shell), so the decrease in deflection in aCSF may be partly due to its exchange. As mentioned above, divalent cations interact more strongly with the PPy chains and thus have greater difficulty exiting the polymer, resulting in less polymer expansion, so one might speculate that the decrease in deflection in aCSF may also be related to that.

In addition, it has been shown that in solutions containing small anions, that they are also exchanged during cycling, despite the presence of the immobile DBS- ${ }^{-[22,69]}$ Interestingly, essentially no $\mathrm{Cl}^{-}$was found in the sample, despite a concentration in aCSF nearly as high as that of $\mathrm{Na}^{+}$. Instead, the oxygen peak in the aCSF samples was $60 \%$ larger (75\% larger if normalizing to the $\mathrm{C}$ peak), and with each $\mathrm{PO}_{4}$ carrying four oxygens and each DBS carrying three, we can tentatively conclude that one $\mathrm{PO}_{4}$ is entering for each two DBSs. This is a surprisingly large amount, given its minute concentration in aCSF $\left(\approx 0.5 \%\right.$ that of $\left.\mathrm{Cl}^{-}\right)$. We have previously seen differences in the affinity of PPy(DBS) to different cations, but this difference to the two anions is particularly large. Prior work with PPy(PPS) tested in sodium phosphate buffer showed an anodic peak, ${ }^{[46]}$ but in our CVs, there were no observable peaks associated with this exchange (compared Figure 3a and c). (It is not the peak at $+0.1 \mathrm{~V}$, since that also appeared in $\mathrm{NaDBS}$.) The $\mathrm{PO}_{4}$ molecule is in the form of $\mathrm{PO}_{4}{ }^{3-}$ at high $\mathrm{pH}$, but becomes increasingly protonated as the $\mathrm{pH}$ is lowered until it becomes $\mathrm{H}_{3} \mathrm{PO}_{4}$ in acidic media. (In CSF, which has a pH of 7.3, the proportions would be expected to be $61 \% \mathrm{HPO}_{4}{ }^{2-}$ and $39 \% \mathrm{H}_{2} \mathrm{PO}_{4}^{-}$.) The local $\mathrm{pH}$ at the surface of the polymer is unknown, but the local $\mathrm{pH}$ is known to be affected by cycling. ${ }^{[58,72]}$ Nevertheless, the molecule is an anion, rather than a cation. Again, half a $\mathrm{PO}_{4}$ per DBS is an enormous amount, and one might have expected that to cause a noticeable reversal in the deflection (Figure 3), particularly given that its reported hydrated radius is nearly as large as that of $\mathrm{Na}^{+}$(Table 1), but it did not. The prior study with PPy(PPS) in sodium phosphate buffer also showed no volume change. ${ }^{[46]}$ It is possible that much slower scans may show actuation strain, or that $\mathrm{PO}_{4}$ has such a small hydration shell in the PPy that it is mechanically "invisible." Further studies would be required to understand this.

\section{Conclusions}

The bending of bilayer bending beams actuated using PPy(DBS) was characterized under physiological conditions similar to those found in the brain. These conditions were simulated by employing aCSF at $37^{\circ} \mathrm{C}$, which contains a mixture of cations, including two divalent cations, as well as a couple of small anions. The roles of both temperature and of the mix of ions were ascertained by making use of a control solution containing only a single type of cation and no mobile anions 
(NaDBS) and by comparing bending at 22 and $37^{\circ} \mathrm{C}$. As discussed above, divalent ions have been shown to ionically crosslink charged polymers, resulting in difficulties in exchanging these ions and producing smaller strains, posing the concern that device performance would degrade in the aCSF. Another concern arose from the presence of the small anions, which in prior work had been shown to produce a reversal of motion, complicating positional control over devices (as well as reducing net strain).

The actuation strain in aCSF at $22{ }^{\circ} \mathrm{C}$ was almost $90 \%$ of that in NaDBS, and furthermore it remained monotonic. The exchanged charge was also virtually the same. Thus, neither the divalent cations nor the small anions had a significant negative impact, even though elemental analysis revealed that all the cationic components of aCSF were present in substantial amounts in the PPy after cycling, in addition to a large amount of $\mathrm{HPO}_{4}{ }^{2-}$ and/or $\mathrm{H}_{2} \mathrm{PO}_{4}{ }^{-}$(one per $2 \mathrm{DBSs}$ ). Interestingly, the ion content in the film did not reflect the solution composition, which had at least 200 times more chlorine than phosphate and 25 times more sodium than all the other cations combined. Temperature exerted a more significant change in behavior. The net strain increased somewhat at $37^{\circ} \mathrm{C}$ in both solutions, and the average bending angle shifted noticeably. These effects will need to be taken into account when designing devices for use in the body. The cyclic voltammograms acquired additional peaks and substantially more charge was exchanged, resulting in a lower efficiency in converting electrical to mechanical work. Nevertheless, it is clear that PPy(DBS) can indeed be used for neural interface and neural probe applications.

\section{Experimental Section}

Bilayer Beam Actuator Fabrication: Devices were fabricated using standard photolithography techniques (Lurie Nanofabrication Facility, University of Michigan). They consisted of a PPy/Au bilayer on a Parylene substrate, with no probe electrode. Photoresist (Shipley 1813, AZ Electronic Materials) was spin-coated onto a $4^{\prime \prime}$ silicon wafer and baked at $95^{\circ} \mathrm{C}$ for $90 \mathrm{~min}$ to serve as a final release layer. Parylene $\mathrm{C}$ was deposited over the resist $(12.9 \pm 0.8 \mu \mathrm{m}$, PDS 2035, Specialty Coating Systems), and after an oxygen plasma clean (PlasmaTherm 790, $150 \mathrm{mT}$, $99 \mathrm{sccm} \mathrm{O}, 100 \mathrm{~W}, 30 \mathrm{~s})$, chromium $(\mathrm{Cr}, 150 \AA)$ and gold ( $\mathrm{Au}, 1500 \AA)$ were evaporated (Enerjet Evaporator, $2 \times 10^{-6} \mathrm{~T}, 10 \AA \mathrm{s}^{-1}$ ) onto the Parylene. A second layer of photoresist was deposited and patterned using a $\mathrm{Cr} /$ glass mask to define the (identical) metal and beam shapes. The metal layers were patterned by wet etching (Transene TFA Au etchant, CR-14 Cr etchant). The Parylene was dry etched using an oxygen plasma (conditions as above, $200 \mathrm{~nm} \mathrm{~min}{ }^{-1}$ etch rate), employing the resist and the metal as a mask. The beams were released by soaking the wafers in acetone, thereby dissolving the first resist layer. They were $13.1 \pm 0.8 \mu \mathrm{m}$ thick, $10 \mathrm{~mm}$ long, and $0.5 \mathrm{~mm}$ wide. The beams were rinsed in isopropanol and water and allowed to air dry before use. PPy(DBS) was polymerized galvanostatically (at constant current) to a thickness of $11.3 \pm 0.8 \mu \mathrm{m}$ onto the Au surface in a solution of $0.1 \mathrm{M}$ pyrrole (Aldrich) and $0.1 \mathrm{M} \mathrm{NaDBS}$ (Aldrich) in deionized (DI) water using a galvanostat/potentiostat (Ecochemie Autolab PGStat 12). The deposition current density was $1 \mathrm{~mA} \mathrm{~cm}{ }^{-2}$. (Polymerizing at higher currents has been shown to reduce actuation strain. $)^{[50-52]}$ A porous carbon counter electrode and $\mathrm{Ag} / \mathrm{AgCl}$ reference electrode (Bioanalytical Systems Inc.) were used during polymerization. Samples were rinsed in DI water and allowed to dry at ambient conditions for at least $24 \mathrm{~h}$. Parylene and PPy thicknesses were measured using scanning electron microscopy (SEM) images (Philips XL30ESEM, $5 \mathrm{kV}$ ) of beam cross-sections. Bilayer devices were stored in closed Petri dishes lined with cleanroom paper wipes.

Actuator Cycling: Electrochemical cycling took place in four conditions: in $0.15 \mathrm{~m} \mathrm{NaDBS}$ or in aCSF (see Table 1) at either 22 or $37^{\circ} \mathrm{C}$. The counter electrode was a $1 \times 1$ " platinum foil and the reference electrode was a dedicated $\mathrm{Ag} / \mathrm{AgCl}$ reference electrode used only for cycling. The counter and reference electrodes were rinsed in water between different solutions. The positive charge density $\left(\mathrm{C} \mathrm{m}^{-3}\right)$ consumed during oxidation was found by integrating the current over the time of the forward sweep from -1.0 to $+0.4 \mathrm{~V}$ and dividing by the measured PPy volume; the negative charge density during reduction was found analogously, and the total charge density was taken as the sum of the absolute values (i.e., energy recovery was not considered).

Beam Tip Deflection, Curvature, and Actuation Strain: Digital video of bilayer actuation was recorded through a microscope (Leica, 10x zoom) at 30 frames per second (Pinnacle Dazzle DVC 100 digital video recorder). Image frames were extracted from the video and sampled every 10 frames, resulting in three frames per second (Quicktime 7 Pro, Apple Inc.). Device dimensions were used for image size calibration. Positional resolution was $22 \mu \mathrm{m} /$ pixel. Three frames are shown overlaid in Figure 6 from a bilayer beam in the fully oxidized and reduced (neutral) states and in the intermediate straight position that was used as a reference. The beam appears to be thicker in the deflected states because it twisted slightly. (For clarification, "reduced" in this context means held at $-1.0 \mathrm{~V}$, determined experimentally to be sufficient to produce the maximum deflection during these cycles; the actual oxidation level is unknown. Likewise, "fully oxidized" means an applied voltage of $+0.4 \mathrm{~V}$.) Image processing was performed on still frames from the video to isolate the beam from the background (Image) software, NIH). An edge-detection algorithm written for this application (Matlab, Mathworks) was used to track the deflection $\delta$ of the tip of the beam. The recorded times from the video and the galvanostat were used to synchronize the cyclic voltammetry (CV) cycles with the deflection. The zero-curvature inflection points were obtained from the frames with the straightest beams. Beam curvature $\kappa$ was calculated from measured tip deflections without assuming small deflections, as described in the Supporting Information.

$\kappa=\frac{2 \Delta x}{(L-\Delta y)^{2}+\Delta x^{2}}$

The actuation strain $\alpha_{\text {PPy }}$ was calculated from the curvature $\kappa^{[33,53,54]}$

$\kappa=\frac{\alpha_{\mathrm{PPy}}}{h_{\text {sub }}} \frac{6 m n(1+m)}{1+4 m n+6 m^{2} n+4 m^{3} n+m^{4} n^{2}}$

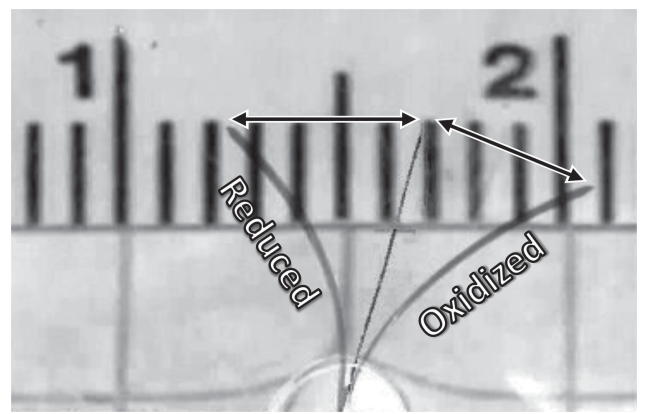

Figure 6. Three superimposed images of beam deflection upon reduction, oxidation, and transitioning midway (overhead view with the face of the beam perpendicular to the page). The ruler scale is in $\mathrm{cm}$. The center position illustrates the zero curvature reference point that was used to determine tip deflections, and the arrows drawn over the image indicate the magnitude of the tip deflection. 
where $h_{\text {sub }}$ is the substrate thickness, $m$ is the PPy to substrate thickness ratio $\left(h_{\mathrm{PPy}} / h_{\text {sub }}\right)$, and $n$ is the ratio of the Young's moduli $\left(E_{\mathrm{PPy}} / E_{\text {sub }}\right)$. An effective $E_{\text {sub }}$ was calculated from the combined substrate layers (see the Supporting Information). The Young's modulus of PPy(DBS) has been shown to change from $200 \mathrm{MPa}$ in the reduced state to $450 \mathrm{MPa}$ in the oxidized state. ${ }^{[23]}$ Therefore, the oxidized state $E_{\mathrm{ppy}}$ was used to find the strain from the curved state (PPy side in) and the reduced state $E_{\mathrm{PPy}}$ was used to find the strain from the backwards-bending curvature. The two strains were summed to determine the effective actuation strain between the oxidized and reduced states.

Electrochemical Break-In: The as-deposited PPy(DBS) is compact, and it typically takes several cycles for the structure to open fully to accommodate ion ingress, ${ }^{[37,55]}$ particularly for thick films. Therefore, the bilayer beams were "primed" by performing ten cyclic voltammograms (CV cycles), ramping the voltage between +0.4 and $-1.0 \mathrm{~V}$ at $10 \mathrm{mV} \mathrm{s}^{-1}$ at room temperature $\left(\mathrm{RT} \approx 22^{\circ} \mathrm{C}\right)$ in $0.15 \mathrm{~m} \mathrm{NaDBS}$. The scan rate of $10 \mathrm{mV} \mathrm{s}^{-1}$ was chosen to enable observation of the shapes and positions of the oxidation and reduction peaks in the $\mathrm{CV}^{[29]}$ and to compare the results to prior work.

Scanning Electron Microscopy and Elemental Analysis: After cycling, the polymer was taken to $0 \mathrm{~V}$ (oxidized) before switching off the voltage. Samples were rinsed in DI water and allowed to dry in air at room temperature for at least $24 \mathrm{~h}$. The final $5 \mathrm{~mm}$ section at the tip of the bilayer was cut off using a razor blade and adhered to a sample holder with double-sided copper/nickel adhesive tape. SEM images were obtained (Philips XL30 ESEM, 5 kV) and the ions in the PPy were identified using energy-dispersive $X$-ray analysis (Phoenix XEDS EDX, EDAX Inc.) with a $20-k V$ accelerating voltage. The spectra were normalized by the maximum intensity sulfur peak, and the resulting profiles were compared (Spectrum View v4.0, EDAX Inc.).

\section{Supporting Information}

Supporting Information is available from the Wiley Online Library or from the author. Supporting information includes cyclic voltammetry and deflection of all twelve bilayers under all four conditions, peak to peak deflections for the samples, variation among samples, deflection upon voltage stepping, transient effects upon voltage stepping, ramping voltage to attenuate initial transient effects, calculation of curvature and actuation strain from deflection measurements, and cross-sectional images showing delamination in some devices.

\section{Acknowledgements}

This work was supported by the Center for Neural Communication Technology, a P41 Resource Center funded by the National Institute of Biomedical Imaging and Bioengineering (NIBIB, P41 EB002030) and supported by the National Institutes of Health $(\mathrm{NIH})$.

Received: November 4, 2013 Published online: February 24, 2014

[1] E. Smela, Adv. Mater. 2003, 15, 481.

[2] C. Immerstrand, K. Holmgren-Peterson, K. E. Magnusson, E. Jager, M. Krogh, M. Skoglund, A. Selbing, O. Inganäs, MRS Bull. 2002, 27, 461.

[3] P. M. George, A. W. Lyckman, D. A. LaVan, A. Hegde, Y. Leung, R. Avasare, C. Testa, P. M. Alexander, R. Langer, M. Sur, Biomaterials 2005, 26, 3511 .

[4] R. A. Green, N. H. Lovell, G. G. Wallace, L. A. Poole-Warren, Biomaterials 2008, 29, 3393.

[5] K. K. C. Lee, N. R. Munce, T. Shoa, L. G. Charron, G. A. Wright, J. D. Madden, V. X. D. Yang, Sens. Actuators A 2009, 153, 230.
[6] E. W. H. Jager, E. Smela, O. Inganäs, Science 2000, 290, 1540.

[7] C. E. Schmidt, V. R. Shastri, J. P. Vacanti, R. Langer, Proc. Natl. Acad. Sci. 1997, 94, 8948.

[8] R. L. Williams, P. J. Doherty, J. Mater. Sci. Mater. Med. 1994, 5, 429.

[9] X. D. Wang, X. S. Gu, C. W. Yuan, S. J. Chen, P. Y. Zhang, T. Y. Zhang, J. Yao, F. Chen, G. Chen, J. Biomed. Mater. Res. A 2004, 68A, 411.

[10] D. D. Ateh, H. A. Navsaria, P. Vadgama, J. R. Soc. Interface 2006, $3,741$.

[11] B. Shapiro, E. Smela, J. Intell. Mater. Syst. Struct. 2007, 18, 181.

[12] A. S. Hutchison, T. W. Lewis, S. E. Moulton, G. M. Spinks, G. G. Wallace, Synth. Met. 2000, 113, 121.

[13] L. Bay, K. West, S. Skaarup, Polymer 2002, 43, 3527.

[14] E. Smela, J. Micromech. Microeng. 1999, 9, 1.

[15] Y. Liu, Q. Gan, S. Baig, E. Smela, J. Phys. Chem. C 2007, 111, 11329.

[16] J. G. Cham, E. A. Branchaud, Z. Nenadic, B. Greger, R. A. Andersen, J. W. Burdick, J. Neurophysiol. 2005, 93, 570.

[17] D. V. Palanker, A. Vankov, P. Huie, S. A. Baccus, J. Neural Eng. 2005, 2, S105.

[18] B. S. Wilson, M. F. Dorman, Hear Res. 2008, 242, 3.

[19] J. A. Saint-Cyr, T. Hoque, L. C. M. Pereira, J. O. Dostrovsky, W. D. Hutchison, D. J. Mikulis, A. Abosch, E. Sime, A. E. Lang, A. M. Lozano, J. Neurosurg. 2002, 97, 1152.

[20] E. D. Daneshvar, D. R. Kipke, E. Smela, (Ed: Y. Bar-Cohen) Proc. SPIE Smart Struct. Mater. (EAPAD) (March 12-15, 2012), San Diego, Vol. 8340, 09.1-09.12.

[21] M. J. M. Jafeen, M. A. Careem, S. Skaarup, Ionics 2010, 16, 1.

[22] S. Skaarup, L. Bay, K. Vidanapathirana, S. Thybo, P. Tofte, K. West, Solid State lonics 2003, 159, 143.

[23] L. Bay, N. Mogensen, S. Skaarup, P. Sommer-Larsen, M. Jorgensen, K. West, Macromolecules 2002, 35, 9345.

[24] A. G. MacDiarmid, Synth. Met. 2001, 125, 11.

[25] A. F. Diaz, J. Bargon, in Handbook of Conducting Polymers, (Ed: T. A. Skotheim), Dekker, New York 1986.

[26] T. Shoa, T. Mirfakhrai, J. D. W. Madden, Synth. Met. 2010, 160, 1280.

[27] J. Kielland, J. Am. Chem. Soc. 1937, 59, 1675.

[28] M. A. Careem, K. P. Vidanapathirana, S. Skaarup, K. West, Solid State lonics 2004, 175, 725.

[29] M. A. Careem, Y. Velmurugu, S. Skaarup, K. West, J. Power Sources 2006, 159, 210.

[30] T. Shimizu, A. Minakata, Eur. Polym. J. 2002, 38, 1113.

[31] R. John, G. G. Wallace, J. Electroanal. Chem. 1993, 354, 145.

[32] M. R. Gandhi, P. Murray, G. M. Spinks, G. G. Wallace, Synth. Met. 1995, 73, 247.

[33] M. Christophersen, B. Shapiro, E. Smela, Sens. Actuators. B 2006, 115, 596.

[34] E. Smela, N. Gadegaard, Adv. Mater. 1999, 11, 953.

[35] Q. B. Pei, O. Inganäs, J. Phys. Chem. 1992, 96, 10507.

[36] S. Skaarup, K. West, L. M. W. K. Gunaratne, K. P. Vidanapathirana, M. A. Careem, Solid State lonics 2000, 136, 577.

[37] H. Yang, J. Kwak, J. Phys. Chem. B 1997, 101, 4656.

[38] Q. B. Pei, O. Inganäs, Solid State lonics 1993, 60, 161.

[39] B. Gaihre, S. Ashraf, G. M. Spinks, P. C. Innis, G. G. Wallace, Sens. Actuators A 2013, 193, 48.

[40] N. Vandestege, P. G. Madden, J. D. Madden, P. A. Anquetil, I. W. Hunter, (Ed: Y. Bar-Cohen), Proc. SPIE Smart Struct. Mater. (EAPAD) (March 2-6, 2003), San Diego, Vol. 5051, 349.

[41] M. Christophersen, E. Smela, Proc. SPIE Smart Struct. Mater. (EAPAD) (February 27 - March 2, 2006), San Diego, Vol. 6168.

[42] S. Fanning, MS thesis, University of Maryland, College Park, MD 2005.

[43] J. D. Madden, D. Rinderknecht, P. A. Anquetil, I. W. Hunter, Sens. Actuators A 2007, 133, 210.

[44] X. Z. Wang, E. Smela, Proc. SPIE Smart Struct. Mater. (EAPAD) (February 27-March 2, 2006), San Diego, Vol. 6168. 
www.MaterialsViews.com

[45] S. Maw, E. Smela, K. Yoshida, R. B. Stein, Synth. Met. 2005, 155, 18

[46] S. S. Pandey, W. Takashima, K. Kaneto, Sens. Actuators B 2004, 102, 142.

[47] W. Takashima, S. S. Pandey, K. Kaneto, Thin Solid Films 2003, 438, 339.

[48] E. C. McNay, R. S. Sherwin, J. Neurosci. Methods 2004, 132, 35.

[49] I. S. Kass, A. A. Bendo, A. E. Abramowicz, J. E. Cottrell, J. Neurosci. Methods 1989, 28, 77.

[50] S. Maw, E. Smela, K. Yoshida, P. Sommer-Larsen, R. B. Stein, Sens. Actuators A 2001, 89, 175.

[51] S. Skaarup, K. West, B. Zachauchristiansen, M. A. Careem G. K. R. Senadeera, Solid State Ionics 1994, 72, 108.

[52] K. West, T. Jacobsen, B. Zachauchristiansen, M. A. Careem, S. Skaarup, Synth. Met. 1993, 55, 1412.

[53] S. P. Timoshenko, J. Opt. Soc. Am. 1925, 11, 233.

[54] J. M. Gere, S. P. Timoshenko, Mechanics of Materials, 4th ed. PWS-KENT Publishing, Company, Boston 1997.

[55] H. Yang, J. Kwak, J. Phys. Chem. B 1997, 101, 774.

[56] B. J. West, T. F. Otero, B. Shapiro, E. Smela, J. Phys. Chem. B 2009, $113,1277$.

[57] M. A. Depaoli, R. C. D. Peres, S. Panero, B. Scrosati, Electrochim. Acta 1992, 37, 1173.

[58] S. Shimoda, E. Smela, Electrochim. Acta 1998, 44, 219.

[59] E. Smela, M. Kallenbach, J. Holdenried, J. Microelectromech. Syst. $1999,8,373$.
[60] P. Chiarelli, A. Della Santa, D. De Rossi, A. Mazzoldi, J. Intell. Mater. Syst. Struct. 1995, 6, 32.

[61] E. Smela, N. Gadegaard, J. Phys. Chem. B 2001, 105, 9395.

[62] T. F. Otero, J. J. López Cascales, G. Vázquez Arenas, Mat. Sci. Eng. C 2007, 27, 18.

[63] T. F. Otero, M. Márquez, I. J. Suárez, J. Phys. Chem. B 2004, 108, 15429

[64] X. Z. Wang, E. Smela, J. Phys. Chem. C 2009, 113, 359.

[65] J. D. W. Madden, P. G. A. Madden, I. W. Hunter, (Ed: Y. Bar-Cohen) Proc. SPIE Smart Struct. Mater. (EAPAD) (March 5-8, 2001), Newport Beach, vol. 4329, 72.

[66] P. A. Anquetil, D. Rinderknecht, N. A. Vandesteeg, J. D. Madden I. W. Hunter, (Ed: Y. Bar-Cohen) Proc. SPIE Smart Struct. Mater. (EAPAD) (March 15-18, 2004), San Diego, vol. 5385, 380.

[67] A. Della Santa, D. De Rossi, A. Mazzoldi, Smart Mater. Struct. 1997, 6,23

[68] A. Della Santa, D. De Rossi, A. Mazzoldi, Synth. Met. 1997, 90, 93.

[69] K. P. Vidanapathirana, M. A. Careem, S. Skaarup, K. West, Solid State lonics 2002, 154, 331.

[70] A. J. Ramponi, J. M. Jaklevic, Technical Report, Lawrence Berkeley Lab., California Univ., Berkeley., LBL-7284, December 1978.

[71] E. D. Daneshvar, E. Smela, D. R. Kipke, (Ed: Y. Bar-Cohen) Proc SPIE Smart Struct. Mater. (EAPAD) (March 7-11, 2010), San Diego, vol. 7642, 1T.1-1T.10.

[72] H. Shinohara, J. Kojima, M. Aizawa, J. Electroanal. Chem. 1989, 266, 297. 